\title{
Gardening as an occupation: a critical review
}

\author{
Michelle York ${ }^{1}$ and Tania Wiseman ${ }^{2}$
}

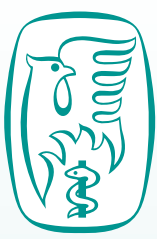

Key words:

Inclusion, gardening, wellbeing, health promoting.

\footnotetext{
${ }^{1}$ Housing and Community Support Worker, Housing Division, Family Mosaic, Southampton.

${ }^{2}$ Senior Lecturer in Occupational Therapy, School of Health Professions, University of Brighton, Eastbourne.
}

Corresponding author: Michelle York, Housing and Community Support Worker, Housing Division, Family Mosaic, 63 St Mary Street, Southampton S014 1NU. Email: michelleayork@yahoo.co.uk

Reference: York M, Wiseman T (2012) Gardening as an occupation: a critical review. British Journal of Occupational Therapy, 75(2), 76-84.

DOI: 10.4276/030802212X13286281651072

(c) The College of Occupational Therapists Ltd. Submitted: 27 January 2011.

Accepted: 14 October 2011.
Purpose: The occupation of gardening has historically generated a wealth of literature. Although espousing its positive impact on wellbeing, evidence is typically anecdotal in nature, with only one major synthesis of reliable evidence to date. This study sought to explore people's experiences and personal meanings of gardening within the literature, from 2003-2010, in order to present a concise body of evidence and to inform occupational therapy practice.

Procedures: A meta-ethnography was used in gathering high quality qualitative studies, synthesising through a process of translations, rather than aggregation, in order to preserve meanings from within a range of culturally specific contexts. Four papers, out of 214 initially identified, met the inclusion criteria employed.

Findings: This study has identified processes within the occupation of gardening in a natural environment, which offer satisfying and meaningful methods of recovery for people who are marginalised within society. This has been shown on an individual and a community health level.

Conclusion: This study has highlighted fundamental links between gardening and wellbeing, and how occupational therapists can broaden practice and have an impact upon health at a community level.

\section{Introduction}

The relationship between occupation and wellbeing is far from a new concept in occupational therapy (Wilcock 2006). Therapeutic use of occupations underpins the philosophy of the profession, with occupations such as gardening being the very essence of the profession's fabric (Holder 2001). Gardening is widely reputed for providing an array of therapeutic benefits to wellbeing, under themes such as increased social inclusion, physical exercise, self-esteem and a spiritual connection (Sempik et al 2005a). Gardening is the occupational form used in social and therapeutic horticulture. Often located within local communities, social and therapeutic horticulture shares similar practices with psychology, social work, occupational therapy and vocational rehabilitation, and is gaining increasing respect and credibility (Fieldhouse and Sempik 2007, Parkinson et al 2011).

The link between occupation and health has been well established through research and is an integral element of several government papers and health guidelines; for example, Occupational therapy interventions and physical activity interventions to promote the mental well-being of older people in primary care and residential care (National Institute for Health and Clinical Excellence [NICE] 2008a) and Mental health and social exclusion (Social Exclusion Unit 2004). Research findings support engagement in occupations that promote physical exercise, social inclusion, life satisfaction, purpose and skill mastery. Research into occupational engagement and health is recognised by the College of Occupational Therapists (2007) as an urgent research theme for informing practice.

\section{Literature review}

Historically, recorded therapeutic benefits of gardening span back to the 1800s, with the belief that working in agricultural fields enhanced life for people 
with mental health issues, through to the use of gardening as activity and therapy for mental and physical rehabilitation in the 1900s to the current 2000s, with gardening used in many contexts (Simson and Straus 2003). A number of previous studies have highlighted the sparse exploration and documentation for the therapeutic benefits of gardening as an occupation (Johnson 1999, Sempik et al 2003, Relf 2005, Stein 2008).

The lack of sound research into gardening was seen as a major hindrance to its viable application as a therapy (Relf 2005). Johnson (1999) found that, from an occupational perspective, studies often regarded gardening in a vocational context, as opposed to a therapeutic one, with lack of consideration of elements such as social, cultural, spiritual and psychological. Stein (2008), in a review of the literature concerning community gardens and health promotion, found significant links to the promotion of physical activity and of psychological wellbeing. These factors were identified as positive influencers against illness and diseases, such as diabetes and colon cancer, and were seen as a strong agent in health promotion.

Sempik et al (2003) conducted a major literature review to pool studies and explore the wider meanings and contexts within gardening as an occupation. Their search stretched from 1970 to 2003. Overwhelmingly, although the literature clearly espoused the therapeutic benefits of gardening, they found studies to be subjective in nature, with poor or ill-defined research designs. Within their literature review, Sempik et al (2003) identified a significant lack of synthesis among published studies. The most recent previous literature review regarding the therapeutic benefits of gardening that they uncovered was by Markee and Janick (1979), which also found poor quality research and lack of synthesis.

After conducting a comprehensive search of the literature, this study has identified four high quality research papers, published since 2003, which explore the therapeutic benefits of gardening. However, there still remains a lack of synthesis within this area of research since Sempik et al (2003).

\section{Purpose of this research}

This study sought to explore the experiences, meanings and implications of gardening as an occupation. A metaethnographic approach was used in order to gather findings from qualitative literature, interpret and create a synthesis of evidence beyond the last literature review of 2003.

The primary research question for the current review was: are there any benefits to using gardening as a therapeutic activity?

\section{Method}

Noblit and Hare (1988) suggested that there are seven stages in conducting a meta-ethnography:

\section{Identifying an area of interest}

This study seeks to explore the benefits of gardening as an occupation, by interpreting the meanings, messages and experiences of people who garden.

\section{Deciding what is relevant}

The focus here is on who the audience is, and the relevant data to gather. The audience for this research comprises occupational therapists, social and therapeutic horticultural therapists, and people engaged in gardening groups within the community. In order to ensure that the experiences of gardening are captured from a wide range of contexts, the following key words were employed in the data collection: 'occupation', 'occupational', 'well-being', 'health', 'gardening', 'horticulture', 'nature', 'therapy', 'therapeutic', 'benefits', 'risks', 'injury', 'psycho-social', 'social inclusion', 'activity', 'groups', 'recovery' and 'connection'. Key words were used in Boolean format, using advanced search options. The following databases were accessed: AMED, CINAHL with Full Text, GreenFILE, ScienceDirect, BMJ, PsycINFO and PsycARTICLES.

Inclusion criteria ensured that only full-text, qualitative, peer-reviewed journal articles were used, in order to ascertain pre-established levels of quality, and studies seeking to explore rather than to measure. Hand searches were conducted from the studies collected. Studies published between January 2003 and May 2010 were included because the last major literature review was conducted in 2003. A critical appraisal checklist, adapted from Letts et al (2007), was employed in the selection of data, in order to ensure continuity of rigour across all studies.

\section{Reading the studies}

Data analysis involves an immersion into the selected studies, paying attention to details in order to allow concepts, metaphors and ideas to emerge from the texts (Noblit and Hare 1988).

\section{Relationship between the studies}

Tables were created, displaying the themes, concepts and ideas across all studies.

\section{Translation}

Comparisons of emerging themes and their interactions across studies were made, while retaining the individual messages or meanings.

\section{Synthesising translations}

Within synthesis, there are three possible routes for distillation of findings, depending on variation (Noblit and Hare 1988). A meta-ethnographic approach allows retention of individual accounts to form a 'whole'. This may be formed of agreeable accounts across all studies, known as 'reciprocal translation', or formed of conflicting accounts, known as 'refutational synthesis'. The third route, 'lines of argument', allows for similarities and dissimilarities within findings to be taken into a new interpretative context. A meta-ethnography is the inscribing of cultural interpretations that other people create, thus generating a reading of a culture: in this case, people who garden (Bryman 2008). 


\section{Presenting the findings}

The final stage is disseminating the study to the relevant audience. This study aims to inform practice, therefore it is relevant that the work is presented to occupational therapists and people working in garden projects.

Within the process of the meta-ethnography, first, second and third order constructs are used. Schutz (1962) identified this process as a transparent method to show emerging metaphors and concepts from participants (first order); the authors' interpretation of these (second order); and how they have been synthesised (third order).

\section{Findings}

Although the search methods yielded 214 studies in total, only four articles satisfied the inclusion criteria. First and second order constructs are arranged into broad categories (Table 1) to summarise the key findings of all four papers. Third order constructs are displayed, evidencing synthesis of these findings. By exploring potential benefits of gardening, this study identifies elements contributing to wellbeing through personal and social agents of change.

\section{Fieldhouse (2003)}

Fieldhouse (2003) explored the social cohesion experienced by members of an allotment group. He used a qualitative approach, with semi-structured in-depth interviews that had a guide of seven questions. Any other data arising from interviews that were new or dis-confirming were explored in a focus group. Two people spoke through an interpreter and the translations were member checked. Nine people participated, with overall member checking through use of the focus group. Four stages of data analysis created rigour to the study: categorisation, with constant comparison to isolate units of meaning; quantitative analysis, with weighing categories; firming up categories, using participants' own language; and relationships between categories, using theory to provide contexts and meaning for occupational performance. Fieldhouse (2003) worked with participants prior to conducting the research, yet employed a reflexive approach in order to minimise bias.

Fieldhouse (2003) clearly identified elements of the allotment that impacted on people's wellbeing. The interplay of the natural environment, activities of gardening and mutually accepting social group combined well. The environment offered a sense of peace and was seen as being away from usual stressors:

I'll never forget that robin sitting on the fork ... without a care in the world ... I just think it's beautiful.

The relationships people had with plants created an emotional response to the environment; people felt that they had a bond or spiritual connection, enhancing mood and arousal levels:

Suddenly you realise you are at one - you don't know what with - but it's a nice feeling.
The environment also offered a sense of stability and safety:

[plants] ... seeing them grow ... a bit of stability in the world. They're not going to go anywhere ... they're not threatening ...

People identified their occupations of gardening as being normal and destigmatising. As people gathered knowledge and skills, and carried out more complicated tasks, their status altered. Positive roles and identities were formed through engagement, which were destigmatised and transferable to a wider community. People thought of the garden as a place not connected with illness or therapy.

The mutually supportive and perceived acceptance from others in the group allowed greater social cohesion. By working towards a common purpose, and sharing experiences and knowledge, people were able to communicate better:

I was part of a team ... my life had a bit of worth to it ... I could achieve something ...

The fascination of growing heightened the sense of personal agency as people realised that they had directly affected the growth of plants. This nurturing of plants was also shown in a collective form when the group were cultivating their harvest together.

\section{Sempik et al (2005b)}

A qualitative approach was used to explore the benefits of organised gardening activities for people who are seen as being vulnerable within society. Purposive sampling was employed, using Thrive - a social and therapeutic horticulture organisation. Thrive created a database of other organisations in the United Kingdom operating within social and therapeutic horticulture. Semi-structured interviews, with a range of formats to fit individuals' abilities to engage, were used. Photographic elicitation allowed greater participation and understanding within this process. Interviews were transcribed and analysed thematically. In total, 137 people were interviewed. Mental health issues ranged from schizophrenia, depression, anxiety, psychosis and bipolar disorder.

Working in the outdoors, surrounded by nature, was found to offer a sense of freedom and an escape from stress. The study highlighted that the natural environments often generated a sense of belonging:

[gardening] ... which had all this time been preparing me, building up my confidence, teaching me new skills, erm, being a, sort of, safe place for me to come while I was building things up for myself.

There was an emotional bond to nature, and pleasure and interest in watching plants grow. The outdoors generated a process of nurturing and represented a sanctuary. Other perceived benefits were that fresh air and physical activity increased people's overall health status. Some had reduced symptoms, or fewer negative thoughts and feelings:

\footnotetext{
I've reduced my anti-convulsants.

it's made me feel fitter ... I've lost excess weight.
} 
Table 1. First and second order constructs showing metaphors and meanings from the four papers, with third order constructs emerging from the meta-ethnographical synthesis

\begin{tabular}{|c|c|c|c|c|}
\hline & Outdoors & Wellbeing & Engagement & Environment and community \\
\hline $\begin{array}{l}\text { Fieldhouse } \\
\text { (2003) }\end{array}$ & $\begin{array}{l}\text { Natural; peace; away } \\
\text { from stressors; growing; } \\
\text { aesthetics and beauty; } \\
\text { relationship with plants. }\end{array}$ & $\begin{array}{l}\text { Destigmatising and normalising } \\
\text { occupations; destigmatised identity; } \\
\text { fresh produce by own efforts; increased } \\
\text { mood; connection to spirituality; } \\
\text { awareness of self; temporal orientation; } \\
\text { flow experiences. }\end{array}$ & $\begin{array}{l}\text { Accepting; mutually supportive; } \\
\text { ease of communication; shared } \\
\text { experiences; common purpose; } \\
\text { generating goals; friendship; } \\
\text { becoming engaged; personal } \\
\text { agency; personal narratives. }\end{array}$ & \\
\hline $\begin{array}{l}\text { Sempik et al } \\
\text { (2005b) }\end{array}$ & $\begin{array}{l}\text { Sanctuary; safety; } \\
\text { belonging; caring; } \\
\text { nurturing; watching } \\
\text { things grow; recovery; } \\
\text { fresh air; aesthetics; } \\
\text { peaceful; healthy; } \\
\text { interesting; pleasurable; } \\
\text { useful; emotional bond } \\
\text { to nature. }\end{array}$ & $\begin{array}{l}\text { Status and roles of gardeners/ } \\
\text { workers; journey of recovery; } \\
\text { development of self; self-confidence; } \\
\text { self-esteem; independence; } \\
\text { connection to nature is healing and } \\
\text { spiritual; increased physical health. }\end{array}$ & $\begin{array}{l}\text { Diverse range of activities and } \\
\text { people; less pressure to perform; } \\
\text { distraction to illness/symptoms; } \\
\text { motivating activities; feeling } \\
\text { useful; increased social skills; } \\
\text { non-medical involvement; } \\
\text { structure and routines; more } \\
\text { responsibility; task completion } \\
\text { and mastery; skill development, } \\
\text { training, education and implied } \\
\text { status; tangible achievements; } \\
\text { teamwork; creative expression; } \\
\text { less work pressure; productivity; } \\
\text { competence in tool use; allowed } \\
\text { to make mistakes; project } \\
\text { involvement and control; setting } \\
\text { personal goals; social over } \\
\text { economic value. }\end{array}$ & $\begin{array}{l}\text { Transferable skills; sustainable } \\
\text { growing; organic methods; } \\
\text { control and choice of healthy } \\
\text { produce; making a difference; } \\
\text { environmental awareness; } \\
\text { personal meaning. }\end{array}$ \\
\hline $\begin{array}{l}\text { Bowker and } \\
\text { Tearle (2007) }\end{array}$ & $\begin{array}{l}\text { Peace; security; beautiful; } \\
\text { increased learning. }\end{array}$ & $\begin{array}{l}\text { Confidence; self-esteem; enjoyable } \\
\text { occupation; pride in efforts and } \\
\text { outcomes. }\end{array}$ & $\begin{array}{l}\text { Increased learning; experiential } \\
\text { learning; deeper understanding; } \\
\text { learn new skills; satisfaction } \\
\text { from achievements. }\end{array}$ & $\begin{array}{l}\text { Knowledge of biodiversity; } \\
\text { environmental awareness; } \\
\text { influencers of local communities; } \\
\text { share knowledge with communities. }\end{array}$ \\
\hline $\begin{array}{l}\text { Jonasson } \\
\text { et al (2007) }\end{array}$ & $\begin{array}{l}\text { Fresh air; solace; increased } \\
\text { learning; recovery; freedom; } \\
\text { satisfaction from aesthetics; } \\
\text { accessible environments; } \\
\text { barriers to functional } \\
\text { performance. }\end{array}$ & $\begin{array}{l}\text { Stimulating and enjoyable; recovery; } \\
\text { learn new skills; receive positive } \\
\text { attention. }\end{array}$ & $\begin{array}{l}\text { Achieving specific results; } \\
\text { accomplishing something real; } \\
\text { positive feedback from others; } \\
\text { matching skills to tasks; } \\
\text { meaningful activities; control } \\
\text { and choice; recovery. }\end{array}$ & \\
\hline $\begin{array}{l}\text { Third order } \\
\text { constructs }\end{array}$ & $\begin{array}{l}\text { Belonging; sanctuary; } \\
\text { peace; aesthetics. } \\
\text { Accessibility affects } \\
\text { performance. }\end{array}$ & $\begin{array}{l}\text { Destigmatising; recovery of self; } \\
\text { connection to something 'real'; } \\
\text { improved self-esteem. }\end{array}$ & $\begin{array}{l}\text { Commonality; structure and } \\
\text { meaning; personal goals and } \\
\text { tangible achievements; control; } \\
\text { personal development; social } \\
\text { value over economic value; } \\
\text { increased learning; competence. } \\
\text { Match skills to tasks. }\end{array}$ & $\begin{array}{l}\text { Social agency on local community; } \\
\text { control and choice of food } \\
\text { consumption. }\end{array}$ \\
\hline
\end{tabular}

The natural environment, range of activities and interactions with others acted synonymously on a person's selfdevelopment:

... now, when I get home, I can also think about things I've done [at the project] ... any problems that have come up ... it's a distraction. I plan what I'm going to do the next day, look forward to it.

Self-esteem, confidence and levels of independence grew as a result of engagement in gardening activities in these environments. New roles or status as a gardener, or worker, had given people a positive identity, and something to share with people outside the group:

The project has given me the confidence to converse with other people. When [neighbours] say come and look at my garden I can talk to them about it.

Engagement in such environments led to a feeling of being connected to something 'real', which offered a sense of healing and a journey of recovery. Status, and the neutralising 
effect of the environment, created a sense of equality among staff and clients, making it feel very different to medical-based services. The focus was not on gardens acting as a form of therapy connected to illness, but on building and demonstrating competence and having a journey to wellness and recovery. Even though people worked hard, had to meet deadlines and had to cope with various responsibilities within their engagement, there was a lack of perceived pressure or of the pressure to perform typical in formal jobs:

... you have to stick at it, do everything right, make no mistakes and that's to get your money and that is like the pressure of your job ...

People were allowed to make mistakes within the work they carried out, and there was a different value attached to the individual and collective efforts of the workers. Emphasis was on the enjoyment and satisfaction of the work carried out, rather than jobs being arbitrary. Projects and workers shifted from an economic to a social value and worth. In the settings studied in this research, many of the individuals became the stakeholders and influencers, making their involvement meaningful, and impacting on their involvement in a wider community. This highlighted a shift for people, who are marginalised and usually perceive or are perceived as being powerless, to becoming the actors in a process of social agents of change within their communities.

\section{Bowker and Tearle (2007)}

Bowker and Tearle (2007) studied the early effects of a garden-based learning project for schoolchildren aged 7-14 years. 'Gardens for Life' was set up in 67 schools in England, Kenya and India. The schools were based in rural, semi-rural and urban populations, and involved children with an absence of illness or disability. An interpretative approach was used in gaining understanding of the perceptions that primary and secondary schoolchildren had on school gardening and their learning. As English was the third language in the Kenyan and Indian schools, there was excellent justification for the qualitative inquiry to use concept maps, contextual observations, and drawings from the children to support interviews. Concept maps and drawings allowed a demonstration of understanding, rather than a process of recall.

Semi-structured interviews took place 6 months from the start of the project's inception. Interviews demonstrated rigour because they were formed on a sampling process of concept maps, which varied in use of concepts and wording. Contextual observations and field notes captured influencing factors within the settings, in order to acknowledge cultural differences and knowledge. Concept grids were generated from interviews with 12 children. Broad concepts found were reduced using depth scoring to test stability, with field notes and interview tapes guiding the interpretative process.

Themes arising from this study clearly showed the influence of learning in the context of a garden, through the use of garden-related activities. The garden environment was reported by all participants for its aesthetic value, as well as offering an area that was peaceful and secure. The garden environments were also seen as a space in which you could have fun and get messy. Working together, the children not only achieved greater learning outcomes of their schoolbased curriculum but also created beautiful spaces in their school gardens. This added a different value to the perception of school, acting as a motivation for some students to attend their lessons:

Flowers are very beautiful in the school because a school without flowers never looks nice at all.

People enjoyed working and learning in the garden, which boosted confidence, self-esteem and their sense of self. Pride was felt for time invested in the garden and the achievements made:

We enjoyed the fruits of our labours - we ate our own school-grown tomatoes.

Through their engagement in the gardening programme, children remarked how their learning processes were heightened. Experiential learning had deepened their understanding and knowledge of both garden-based and school curriculum-based teaching. Within the processes of using the garden as a learning environment, the children were able to experience learning processes directly, with tangible and real outcomes. Deeper understanding of their science curriculum was gained by observing the tangible effects of weather conditions on plant life.

The children also found that, through direct involvement in their gardens and through the knowledge base they were acquiring, they had a more positive role in, and effect on, their local communities. This was generated when imparting their knowledge and skills to people in the community, such as farmers, regarding maintenance and production of crops. In this way the children were acting on their communities, with a new role, and creating influence. The children had greater awareness and knowledge of biodiversity, sustainable farming and environmental issues. They used positive slogans and phrases to state that not only a garden but also a whole planet must be tended to:

We must care for our plants to care for the world.

\section{Jonasson et al (2007)}

This study used a qualitative method and a phenomenological approach to explore the benefits of activities in a training garden for people with neurological impairment. Fourteen people, who attended an outpatient rehabilitation unit for neurological impairments, participated in the study. Variation was present in diagnoses: multiple sclerosis $(n=3)$, stroke $(n=10)$ and brain tumour $(n=1)$; in mobility levels: three wheelchair users and six people using walking aids; and in functional ability: three people wished to maintain existing function and 11 to regain lost function. Findings of this study may, therefore, not be representative for the wider spectrum of people with neurological disorders, because the predominant group were those who had had a stroke. 
Several processes were used in the data analysis: familiarising with data; gathering into significant statements; and comparison across findings to identify inherent meaning. Data were then condensed to show patterns and emerging categories. Rigour was evident as two researchers worked in parallel in the analysis of data, with collaborative working to establish agreement. A third researcher critically judged findings until consensus was reached.

The study highlighted that in aiming to offer a less pressurised therapeutic environment, then working in nature and the outdoors generated stimulating and satisfying outcomes. People found the benefits of receiving fresh air and sunshine, in aesthetic surroundings, to have positive effects on their body and mind:

When I am out in the garden among everything that's growing

I get a magnificent feeling of wellbeing ... speeding up the whole process of recovery.

Learning new skills, or maintaining existing ones, also created tangible effects within the garden environment, often resulting in positive feedback and attention from people outside the group:

I want appreciation, my body feels better after being praised

in the same way that I feel worse after being told off

Learning was also seen as being enjoyable when in this environment, because the outdoors made the training seem easier. Significantly, it was the achieving of specific results in an environment that felt real and meaningful which had great effect on people:

It is really satisfying to do things when the result is visible, it is the best form of rehabilitation.

The study also highlighted that the design and accessibility of the garden area, and matching skills to tasks, acted as barriers to occupational performance for some participants. People using wheelchairs found it difficult to access the environment and to perform tasks successfully. Demands of certain activities were related to a person's level of confidence in his or her capabilities or to coping with tasks that were difficult:

It wasn't all that easy but it could be done, the sensation in my fingers is poor so it wasn't all that easy.

\section{Discussion}

Synthesis of these studies was achieved by searching across the studies to determine a translation of the metaphors that emerged within the findings (see Table 1). A line of argument emerged as the similarities and dissimilarities across studies formed new ideas.

All four studies showed that the natural, outdoor environment acted as a democratising, neutral platform, on which people could develop on emotional, cognitive, physical and spiritual levels. The psychological benefits of the natural environment are well documented, and demonstrate that calming effects, reduction of stress and a switch to a different, more stimulating and revitalising attention, may be useful in a process of recovery (Kaplan 1995). A process of being in the outdoors usually involved physical activity. All four papers remarked how physical engagement increased a sense of wellbeing. The link between physical activity and wellbeing is documented in a wealth of research (Fogarty and Happell 2005). People who are more at risk of being isolated from typical community-based activity and involvement may be more at risk of physical ill-health due to lower physical activity (Social Exclusion Unit 2004). In Jonasson et al (2007), the design and accessibility of the garden environment decreased the overall occupational performance of individuals using wheelchairs to mobilise. Engagement and wellbeing is increased in welldesigned, accessible open green spaces (Annerstedt 2009). Creating accessible open green spaces in the community to increase engagement is central to recent health policy (NICE 2008b). Fieldhouse (2003) and Sempik et al (2005b) found that physical engagement in gardening activities led to feelings of better physical health. Sempik et al (2005b) also identified fewer negative feelings and thoughts, and some reduction in medications.

Gardening activities in a natural environment offered a neutral platform in which a 'new self' could be tried out. The psychological phenomenon of personal agency relates to how we can imagine and create a new sense of self through our actions. Personal agency in motion is demonstrated in the choices we make and the responsibility we have in making these decisions (Frie 2008).

This sense of personal agency was evident within all of the papers:

1. On an affective level of nurturing an aesthetically pleasing and soothing environment

2. In the acquisition of skills and knowledge; and within a process of recovering a positive sense of self (Fieldhouse 2003, Sempik et al 2005b, Bowker and Tearle 2007, Jonasson et al 2007).

Fieldhouse (2003) and Sempik et al (2005b) found that, by nurturing the natural environment, people related more easily to the concept and act of self-nurturing. This was also seen on a collective level when harvesting produce (Fieldhouse 2003). Healthy produce, maintained and harvested by the group, was seen metaphorically as a process of 'feeding' the group's ethos and collective identity. This shows a transformation from an autonomous process of personal agency into a broader sphere of social agent of change. In similar ways, Bowker and Tearle (2007) found that the schoolchildren were feeding their schools' identity by adding aesthetic value to it, not only in motivating themselves to attend but also in the tangible results of their learning outcomes. This was extended on a wider level because the children were concerned with taking care of their communities, their country and the planet.

Jonasson et al (2007) showed how the use of gardening activities facilitated the maintenance and relearning of skills for people with neurological impairments. Personal 
agency was seen through the use of stimulating, interesting and enjoyable activity within the garden, taking the focus away from hard work or medical-based therapy. The environment, activity and 'reward' worked synergistically towards a sense of wellbeing, recovery and positive rehabilitation outcomes. 'Reward' in this study involved receiving positive praise, and in working towards something that felt real and meaningful. Gardening is seen as having purpose and meaning, containing inherent intrinsic motivation, and associated with a process of a normal, healthy lifestyle (Parkinson et al 2011). Jonasson et al (2007), discussing how people struggled and lost their confidence carrying out tasks, highlighted a requisite core skill of occupational therapists - activity analysis - in maximising occupational performance (Turner et al 2005).

Neutralising effects of engaging in gardening activities within the natural environment meant that people worked towards, and achieved, goals in a new way (Fieldhouse 2003, Sempik et al 2005b, Bowker and Tearle 2007, Jonasson et al 2007). Gardening itself was viewed as an ordinary occupation, with no attachment to illness or therapy, and took the stigma out of the activities in which people were engaging (Fieldhouse 2003, Sempik et al 2005b). Processes within these environments lend themselves to a recovery approach. People were able to build a positive identity through meaningful and satisfying engagement, focusing on their wellness and strengths, rather than on illness and diagnosis (Recovery Devon Group 2010). People worked together, trying out new or difficult tasks within their environment, developing their skill and knowledge base.

As a person developed more confidence in his or her own capabilities, his or her sense of self altered. Identities became more positive as people built up their skill and knowledge base within the environment, developing a positive sense of self, roles and status. Bandurra (1989) stated that wellbeing requires a developed sense of personal efficacy. On a societal level, we must counter many difficulties, inequalities, frustrations, setbacks and adversities; in coping with these, we develop our resilience.

Participants within the studies by Fieldhouse (2003), Sempik et al (2005b) and Jonasson et al (2007) consisted of people who had experience of living with an illness or disability. Commonalities within the groups had a democratising effect, with individuals feeling equal to one another. Within the harmonising effect of equality, people related to each other more easily, shared their experiences and generated personal narratives (Fieldhouse 2003, Sempik et al 2005b).

We may ask why a group can work well within such settings, yet be distilled when it operates on a wider community level? Influences from the industrialisation era still pervade societal values, and filter through into health and social care services (Wilcock 2006). Wilcock (2006) stated that there is an economic, rather than a social or emotional, capital and value placed on individuals. An individual's place in society may be judged from his or her economic productivity or 'cost'. This had an affirming effect on the groups studied by Fieldhouse (2003), Sempik et al (2005b) and Jonasson et al (2007). Emerging themes resonated around people's perceived place within society; their worth on a societal level, including worker status; their inclusion within society; and their influence upon society. Often people who are marginalised face greater isolation and disenfranchisement from their communities through occupational deprivation and alienation (Social Exclusion Unit 2004, Wilcock 2006).

Fieldhouse (2003) and Sempik et al (2005b) showed how work-related activities were empowering when carried out in the garden groups. Working in a destigmatised environment with people who had similar experiences fostered greater recovery processes of gaining skills and confidence. The lack of pressure, and acceptance of making mistakes in a forgiving and nurturing environment, created positive shifts. Work-related social situations commonly affect job retention for people with mental health issues (Mueser et al 2005). Sempik et al (2005b) found that people valued an unpaid or low paid job at their community garden group over a well-paid job in the community. A greater sense of wellbeing was derived from 'making a difference' within the environment, as well as successful and satisfying group and personal growth. People were empowered through collaborative involvement and action in the operation of their organisations (Fieldhouse 2003, Sempik et al 2005b).

Many of the organisations operated on some level within their local communities, through events such as open days and plant sales. Greater social participation can be achieved through such mechanisms, and is supported by the individual having a stronger sense of self, knowledge and skills from engagement within the gardening organisations. In this way, the individual makes the transformational shift from being the influenced, to the influencer, on a wider community and societal level, creating a social agent of change. This shift creates exciting potentials for the understanding of occupation and health when focusing on the social determinants of wellbeing within the realm of public health and community development, and on the roles in which occupational therapists can work (Wilcock 2006).

\section{Limitations of the study}

Noblit and Hare (1988) wrote extensively on the methodology of conducting a meta-ethnography. The process allows for qualitative studies to be synthesised, yet variations exist on the exact nature of translation and synthesis of emerging metaphors and concepts. Since Noblit and Hare (1988) proposed meta-ethnography as a method for researching, several attempts have been made to devise comprehensive and transparent procedures. For this study, an example from NICE was followed (Campbell et al 2006). When reading the four papers and exploring the first and second order concepts, it is difficult to judge what the authors chose to edit from their original findings and discussion, and whether this would have altered the research findings. 


\section{Implications for practice}

This study sought to inform practice within the context of gardening as an occupation, and has identified three areas in which there are implications for practice:

1. Gardening is a beneficial occupation, which is established through evidence that the natural environment, use of gardening activities, the social group, opportunities to redefine personal identity and roles through a nurturing process, and skill development increase wellbeing. Despite this, activity analysis and grading, and accessibility of the environment, remain as considerations.

2. Professionals working within a gardening setting are able to harness the personal and social agents of change, and to work to establish and maintain links to the wider community. This promotes social inclusion and the push towards community development as a determinant of health.

3. Occupational therapists should collaborate with organisations operating within the voluntary and community sector in order to use their unique services.

Further research is needed to explore gardening and wellbeing, focusing on recovery and psychosocial interaction on an individual and wider level of participation.

\section{Conclusion}

The occupation of gardening in the natural environment was shown to increase wellbeing amongst individuals. Being in the outdoors offered a calming, neutral, destigmatised platform, where people felt connected to something real. Physical activity whilst engaging in gardening increased physical health and fitness, with positive effects on mental health. The environment and occupational form created the genesis of a 'new self', configured through demonstrable competency within tasks, and the act of nurturing the environment and the people within the group. This sense of personal agency operated within the same dimension as a recovery approach.

Gardening in an outdoor natural environment was found to aid learning processes and enrich understanding through physical participation, experiential learning and tangible outcomes. Physical skills were re-learnt, or maintained in ways that offered satisfaction and personal meaning. A process of social agent of change was identified, in how people influenced and shaped their wider communities. People were 'making a difference' in doing something 'bigger' on a societal level by caring for the planet; providing examples of successful sustainable practices for garden projects; and, for future collaboration of services, promoting social inclusion and integration for people who are marginalised.

\section{Acknowledgements}

This research was carried out as part of an MSc. Sincere thanks extend to the community gardening group, Exchange, who gave me the reason for conducting this research, through the Community University Participation Programme, University of Brighton; and to Thrive.

Conflict of interest: None declared.

\section{Key findings}

- Gardening in the natural environment offers meaningful, satisfying opportunities to increase wellbeing and recovery.

- Social agent of change occurs through successful gardening projects, leading to wider community integration.

\section{What the study has added}

This study has created a clear synthesis of evidence supporting the use of gardening for enhancing wellbeing.

\section{References}

Annerstedt M (2009) Health promotion, environmental psychology and sustainable development - a successful ménage-à-trois. Global Health Promotion, 16(49), 49-52.

Bandurra A (1989) Human agency in social cognitive theory. American Psychologist, 44(99), 1175-84.

Bowker R, Tearle P (2007) Gardening as a learning environment: a study of children's perceptions and understandings of school gardens as part of an international project. Learning Environment Resources, 10(2), 83-100.

Bryman A, ed (2008) Social research methods. 3rd ed. Oxford: Oxford University Press.

Campbell R, Britten N, Pound P, Donovan J, Morgan M, Pill R, Pope C (2006) Using meta-ethnography to synthesise qualitative research. In: C Pope, ed. Moving beyond effectiveness in evidence synthesis - methodological issues in the synthesis of diverse sources of evidence. London: National Institute for Health and Clinical Excellence.

College of Occupational Therapists (2007) Building the evidence for occupational therapy - priorities for research. London: COT.

Fieldhouse J (2003) The impact of an allotment group on mental health clients' health, wellbeing and social networking. British Journal of Occupational Therapy, 66(7), 286-96.

Fieldhouse J, Sempik J (2007) 'Gardening without borders': reflections on the results of a survey of practitioners of an 'unstructured' profession. British Journal of Occupational Therapy, 70(10), 449-53.

Fogarty M, Happell B (2005) Exploring the benefits of an exercise programme for people with schizophrenia: a qualitative study. Issues in Mental Health Nursing, 26(3), 341-51.

Frie R (2008) Psychological agency: theory, practice, and culture. California: MIT Press.

Holder V (2001) The use of creative activities within occupational therapy. British Journal of Occupational Therapy, 64(2), 103-05.

Johnson WT (1999) Horticultural therapy: a bibliographic essay for today's health care practitioner. Complementary Health Practice Review, 5(3), 225-32.

Jonasson I, Marklund B, Hildingh C (2007) Working in a training garden: experiences of patients with neurological damage. Australian Occupational Therapy Journal, 54(4), 266-72.

Kaplan S (1995) The restorative benefits of nature: toward an integrative framework. Journal of Environmental Psychology, 15(3), 169-82.

Letts L, Wilkins S, Law M, Stewart D, Bosch J, Westmorland M (2007) Guidelines for critical review form: qualitative studies (version 2.0). Qualitative Review Form Guidelines. Hamilton, ON: McMaster University. Available at: $h$ ttp://www.srsmcmaster.ca/Portals/20/pdf/ebp/qualguidelines _version2.0.pdf Accessed 30.09.11. 
Markee KM, Janick J (1979) A bibliography for horticultural therapy (19701978): comparison of literature search techniques in an interdisciplinary field. Horticultural Science, 14(6), 692-97.

Mueser KT, Aalto S, Becker DR, Ogden JS, Wolfe RS, Schiavo D, Wallace CJ, Xie $\mathrm{H}$ (2005) The effectiveness of skills training for improving outcomes in supportive employment. Psychiatric Services, 56(10), 1254-60.

National Institute for Health and Clinical Excellence (2008a) Occupational therapy interventions and physical activity interventions to promote the mental well-being of older people in primary and residential care. NICE Public Health Guidance 16. London: NICE. Available at: http://www.nice.org.uk/nicemedia/live/11999/42395/42395.pdf Accessed 30.09.11.

National Institute for Health and Clinical Excellence (2008b) Promoting and creating built or natural environments that encourage and support physical activity. Workplace health promotion: how to encourage employees to be physically active. NICE Public Health Guidance 13. London: NICE. Available at: http://www.nice.org.uk/nicemedia/live/ 11917/38983/38983.pdf Accessed 30.09.11.

Noblit GW, Hare RD (1988) Meta-ethnography: synthesising qualitative studies. Qualitative research methods. Volume 11. Newbury Park, CA: Sage.

Parkinson S, Lowe C, Vecsey T (2011) The therapeutic benefits of horticulture in a mental health service. British Journal of Occupational Therapy, 74(11), 525-34.

Recovery Devon Group (2010) Making recovery a reality. Recovery - concepts and application. London: Sainsbury Centre for Mental Health. Available at: http://www.scmh.org.uk/pdfs/recovery_concepts.pdf Accessed 30.09.11.
Relf PD (2005) The therapeutic value of plants. Pediatric Rehabilitation, 8(3), 235-37.

Schutz A (1962) The problem of social reality. Collected papers: 1. The Hague: Martinus Nijhoff Publishers.

Sempik J, Aldridge J, Becker S (2003) Social and therapeutic horticulture: evidence beyond the messages from research. Research Team, Loughborough University. Loughborough: Media Services, Loughborough University/Thrive.

Sempik J, Aldridge J, Becker S (2005a) In touch with the earth. Mental Health Today, September, 23-26.

Sempik J, Aldridge J, Becker S, eds (2005b) Health, well-being and social inclusion - therapeutic horticulture in the UK. Bristol: The Policy Press, University of Bristol, in association with Thrive.

Simson SP, Straus MC, eds (2003) Horticulture as therapy - principles and practice. New York: Food Products Press.

Social Exclusion Unit (2004) Mental health and social exclusion. Social Exclusion Unit report. London: Office of the Deputy Prime Minister. Available at: http://www.socialinclusion.org.uk/publications/SEU.pdf Accessed 30.09.11.

Stein M (2008) Community gardens for health prevention and disease prevention. International Journal for Human Caring, 12(3), 47-52.

Turner A, Foster M, Johnson S, eds (2005) Occupational therapy and physical dysfunction: principles, skills and practice. 5th ed. London: Churchill Livingstone.

Wilcock A (2006) An occupational perspective of health. 2nd ed. Thorofare, NJ: Slack. 